\title{
Adaptability and phenotypic stability of common bean genotypes through Bayesian inference
}

\author{
A.M. Corrêa ${ }^{1}$, P.E. Teodoro ${ }^{2}$, M.C. Gonçalves ${ }^{3}$, L.M.A. Barroso ${ }^{4}$, \\ M. Nascimento ${ }^{4}$, A. Santos ${ }^{5}$ and F.E. Torres ${ }^{1}$ \\ ${ }^{1}$ Departamento de Fitotecnia, Universidade Estadual do Mato Grosso do Sul, \\ Aquidauana, MS, Brasil \\ ${ }^{2}$ Departamento de Biologia Geral, Universidade Federal de Viçosa, Viçosa, \\ MG, Brasil \\ ${ }^{3}$ Departamento de Estatística, Universidade Federal da Grande Dourados, \\ Dourados, MS, Brasil \\ ${ }^{4}$ Departamento de Estatística, Universidade Federal de Viçosa, Viçosa, MG, \\ Brasil \\ ${ }^{5}$ Departamento de Melhoramento Genético, \\ Universidade Estadual do Norte Fluminense Darcy Ribeiro, \\ Campo dos Goytacazes, RJ, Brasil \\ Corresponding author: P.E. Teodoro \\ E-mail: eduteodoro@hotmail.com \\ Genet. Mol. Res. 15 (2): gmr.15028260 \\ Received December 11, 2015 \\ Accepted January 18, 2016 \\ Published April 26, 2016 \\ DOI http://dx.doi.org/10.4238/gmr.15028260
}

\begin{abstract}
This study used Bayesian inference to investigate the genotype $\mathrm{x}$ environment interaction in common bean grown in Mato Grosso do Sul State, and it also evaluated the efficiency of using informative and minimally informative a priori distributions. Six trials were conducted in randomized blocks, and the grain yield of 13 common bean genotypes was assessed. To represent the minimally informative a priori distributions, a probability distribution with high variance was used, and a meta-analysis concept was adopted to represent the
\end{abstract}


informative a priori distributions. Bayes factors were used to conduct comparisons between the a priori distributions. The Bayesian inference was effective for the selection of upright common bean genotypes with high adaptability and phenotypic stability using the Eberhart and Russell method. Bayes factors indicated that the use of informative a priori distributions provided more accurate results than minimally informative a priori distributions. According to Bayesian inference, the EMGOPA-201, BAMBUÍ, CNF 4999, CNF 4129 A 54, and CNFv 8025 genotypes had specific adaptability to favorable environments, while the IAPAR 14 and IAC CARIOCA ETE genotypes had specific adaptability to unfavorable environments.

Key words: Phaseolus vulgaris L.; Bayes factor; Informative prior; Genotype $\mathrm{x}$ environment interaction

\section{INTRODUCTION}

Brazil is the largest producer of common bean (Phaseolus vulgaris L.), with a production estimated at 3.0 million tons in 2014 (FAO, 2015) and average productivity of $0.94 \mathrm{Mg} / \mathrm{ha}(\mathrm{CONAB}, 2015)$. However, this productivity is low considering its productive potential, which can reach $4500 \mathrm{~kg} / \mathrm{h}$. There are several reasons for this issue, such as the inappropriate use of genotypes that are not adapted to the various growing regions.

A major challenge for plant breeders is determining the appropriate common bean genotypes for the various regions of Brazil due to genotype $\mathrm{x}$ environment (GE) interactions, which determine the differential response of genotypes among environments. To reduce the effects of GE interactions, it is convenient to know their magnitude and to identify more stable genotypes adapted to specific environments (Cruz and Regazzi, 2007). In this context, several methods to study adaptability and stability have been used to measure GE interactions in common bean (Coimbra et al., 1999; Carbonell et al., 2004; Ribeiro et al., 2009; Pereira et al., 2009, 2011; Torga et al., 2013), predominantly based on linear regression models (Eberhart and Russell, 1966) and multivariate analyses, such as additive main effects and multiplicative interaction analysis (AMMI) (Gauch, 2006).

Traditional methods that predict genotype performances in multiple environments are based on a "classic" (or frequentist) approach to statistics, which estimates one or more parameters from a set of observations. The variables are used to make statements about a statistical model, which is characterized in terms of parameters with a "true" value (Couto et al., 2015). An alternative to classical statistical inference is Bayesian inference, which is based on the principles of likelihood and the incorporation of a priori information (Silva et al., 2013).

This approach uses three basic concepts: initial information (a priori probability), generally assumed as a joint probability law on the parameters before obtaining the private information of the samples $\mathrm{y}_{1}, \ldots, \mathrm{y}_{\mathrm{n}}$ of the random variable; the probabilistic model of random response variable y, with which it obtains the likelihood of the sample; and Bayes' theorem, which combines the a priori information and the likelihood function and generates a posterior distribution (Cotes et al., 2006; Silva et al., 2013). Nascimento et al. (2011) formulated a Bayesian approach using the Eberhart and Russell (1966) method to evaluate GE interaction, and concluded that the selection of genotypes in different environments was most accurate 
when a priori information was used. It is a robust statistical procedure with many possible applications, but its use in plant genetic improvement is still limited (Teodoro et al., 2015).

Thus, the aim of this study was to use Bayesian inference to investigate the GE interaction in common bean grown in Mato Grosso do Sul State, and we also evaluated the efficiency of using informative and minimally informative a priori distributions.

\section{MATERIAL AND METHODS}

Six trials (environments) were conducted from 2002 to 2006. The environments were composed of a combination of location, growing season, and agricultural year (Table 1). Thirteen genotypes (Rudá, Aporé, Xamego, Pérola, Ouro Negro, Diamante Negro, IAPAR 14, EMGOPA 201, and IAC CARIOCA ETE and the lines BAMBUÍ, CNF 4999, CNF 4129 A 54, and CNFv. 8025) were evaluated in a randomized block design with three replications. Experimental units consisted of four $1.5 \mathrm{~m}$ long rows of plants spaced $0.50 \mathrm{~m}$ apart. Grain yield was evaluated in the central rows, being expressed in $\mathrm{Mg} / \mathrm{ha}$, considering the area harvested and adjusting the data for $13 \%$ moisture.

Table 1. Environments, site, climate, latitude, longitude, altitude, harvest, and agricultural year of trials conducted in the State of Mato Grosso do Sul.

\begin{tabular}{l|l|l|c|c|c|c|c}
\hline Environment & Site & Climate $^{1}$ & Latitude & Longitude & Altitude $(\mathrm{m})$ & Harvest & Agricultural year \\
\hline 1 & Dourados & Cwa & $22^{\circ} 12^{\prime}$ & $54^{\circ} 48^{\prime}$ & 452 & Rainy & $2000 / 2001$ \\
\hline 2 & Dourados & Cwa & $22^{\circ} 12^{\prime}$ & $54^{\circ} 48^{\prime}$ & 452 & Drought & $2000 / 2001$ \\
\hline 3 & Aquidauana & Aw & $20^{\circ} 20^{\prime}$ & $55^{\circ} 48^{\prime}$ & 207 & Drought & $2000 / 2001$ \\
\hline 4 & Dourados & Cwa & $22^{\circ} 12^{\prime}$ & $54^{\circ} 48^{\prime}$ & 452 & Rainy & $2001 / 2002$ \\
\hline 5 & Dourados & Cwa & $22^{\circ} 12^{\prime}$ & $54^{\circ} 48^{\prime}$ & 452 & Drought & $2001 / 2002$ \\
\hline 6 & Aquidauana & Aw & $20^{\circ} 20^{\prime}$ & $55^{\circ} 48^{\prime}$ & 207 & Drought & $2001 / 2002$ \\
\hline 7 & Aquidauana & Aw & $22^{\circ} 12^{\prime}$ & $54^{\circ} 48^{\prime}$ & 207 & Drought & $2002 / 2003$ \\
\hline 8 & Aquidauana & Aw & $20^{\circ} 20^{\prime}$ & $55^{\circ} 48^{\prime}$ & 207 & Drought & $2003 / 2004$ \\
\hline 10 & Aquidauana & Aw & $22^{\circ} 12^{\prime}$ & $54^{\circ} 48^{\prime}$ & 207 & Drought & $2004 / 2005$ \\
\hline 11 & Dourados & Cwa & $22^{\circ} 12^{\prime}$ & $54^{\circ} 48^{\prime}$ & 452 & Rainy & $2005 / 2006$ \\
\hline 12 & Dourados & Cwa & $22^{\circ} 12^{\prime}$ & $54^{\circ} 48^{\prime}$ & 452 & Drought & $2005 / 2006$ \\
\hline
\end{tabular}

${ }^{1}$ According to Köppen-Geiger classification.

Data were subjected to individual ANOVA, and fixed and other treatment effects were considered to be random. The results indicated that the relationship between the highest and lowest mean square of the individual ANOVA of the residues did not exceed a 7:1 ratio, which allowed the implementation of the joint analysis of trials (Banzatto and Kronka, 2006). The data were subsequently subjected to adaptability and stability analyses using the Eberhart and Russell (1966) method.

The adopted linear regression model of Eberhart and Russell (1966) was:

$$
Y_{\mathrm{ij}}=\beta_{0 \mathrm{i}}+\beta_{\mathrm{li}} \mathrm{I}_{\mathrm{j}}+\psi_{\mathrm{ij}}
$$

(Equation 1)

where $Y_{i j}$ is the observed mean of genotype $i$ in environment $j ; \beta_{0 i}$ is the linear coefficient related to $i$-th genotype; $\beta_{\mathrm{li}}$ is the regression coefficient of genotype $\mathrm{i}$; $\mathrm{I}_{\mathrm{j}}$ is the environmental index $\mathrm{j}$; and $\Psi_{\mathrm{ij}}$ represents the random errors that are compounded by the regression deviation of 
genotype $i$ in environment $j$ and by the mean error associated with the mean. The environmental index was estimated using the following equation:

$$
I_{j}=\bar{Y}_{j}-\bar{Y}_{m} \text {, with } \sum_{j=1}^{n} I_{j}=0
$$

where $\bar{Y}_{m}$ is the overall mean; $\bar{Y}_{j}$ is the mean of environment $j$; and $n$ is the number of environments.

According to the Eberhart and Russell (1966) method, genotype adaptability was measured using the parameter $\beta_{1 \mathrm{i}}$, while the stability of behavior was evaluated using the variance of the regression deviations $\left(\sigma_{\mathrm{di}}^{2}\right)$ and the coefficient of determination $\left(\mathrm{R}^{2}\right)$, which is an auxiliary measure for stability assessment (Cruz and Regazzi, 2007). The $\mathrm{R}^{2}$ value indicates acceptable predictability when $\sigma^{2}$ id significant and $\mathrm{R}^{2}$ is higher than $80 \%$. Using this frequentist approach, the hypotheses of interest are: $\mathrm{H}_{0}: \beta_{\mathrm{li}}=1$ versus $\mathrm{H}_{1}: \beta_{\mathrm{li}} \neq 1$ and $\mathrm{H}_{0}: \sigma^{2}$ $=0$ versus $\mathrm{H}_{1}: \sigma_{\mathrm{di}}^{2}>0$, which are assessed using $t$ and $\mathrm{F}$ statistics, respectively.

For the Bayesian analysis, we considered all genotypes that were evaluated in Corrêa et al. (2009), which were used as references for the specification of a priori distributions (Table 2).

Table 2. Estimates and means $\left(\beta_{0 \mathrm{i}}\right)$ associated with adaptability $\left(\beta_{1 \mathrm{i}}\right)$, stability $\left(\sigma_{\mathrm{di}}^{2}\right)$, and the coefficient of determination $\left(\mathrm{R}^{2}\right)$, which were obtained using the Eberhart and Russell method (1966), as described in Corrêa et al. (2009).

\begin{tabular}{l|c|c|c|c}
\hline Genotype & $\beta_{0 \mathrm{i}}(\mathrm{Mg} / \mathrm{ha})$ & $\beta_{\mathrm{li}}$ & $\sigma^{2} \mathrm{di}$ & $\mathrm{R}^{2}$ \\
\hline RUDÁ & 2.18 & 0.97 & 128,693 & 67.33 \\
\hline APORÉ & 2.31 & 0.75 & 110,006 & 58.78 \\
\hline XAMEGO & 2.04 & 0.93 & 95,113 & 71.24 \\
\hline PÉROLA & 1.71 & 0.82 & 87,035 & 67.51 \\
\hline OURO NEGRO & 1.96 & 1.32 & 212,871 & 70.59 \\
\hline DIAMANTE NEGRO & 1.75 & 0.99 & 36,570 & 85.75 \\
\hline IAPAR 14 & 1.87 & 0.69 & 151,370 & 47.49 \\
\hline EMGOPA-201 & 2.31 & 1.13 & 270,922 & 58.40 \\
\hline IAC CARIOCA ETE & 1.73 & 0.61 & 121,449 & 45.89 \\
\hline BAMBUÍ & 1.63 & 1.31 & 393,732 & 57.04 \\
\hline RIO TIBAGI & 1.76 & 1.17 & 96,833 & \\
\hline CNF 4129 A 54 & 1.36 & 1.06 & 199,921 & 79.43 \\
\hline CNFv 8025 & 1.97 & 1.24 & 245,919 & 62.04 \\
\hline
\end{tabular}

With the Bayesian approach, we considered the following statistical model, developed by Nascimento et al. (2011):

$$
\mathrm{Y}_{\mathrm{ij}}=\beta_{0 \mathrm{i}}+\beta_{\mathrm{li}} \mathrm{I}_{\mathrm{j}}+\psi_{\mathrm{ij}}
$$

where each $Y_{i j}$ observation was assumed to have the following distribution:

$$
\mathrm{Y}_{\mathrm{ij}} \sim \mathrm{N}\left(\beta_{0 \mathrm{i}}+\beta_{\mathrm{li}} \mathrm{I}_{\mathrm{j}}: \sigma_{\mathrm{di}}^{2}\right)
$$

where the likelihood function for each genotype $\mathrm{i}$ is given by: 


$$
\mathrm{L}_{\mathrm{i}}\left(\beta_{0 \mathrm{i}}, \beta_{\mathrm{i}}, \sigma_{\mathrm{i}}^{2}, \mathrm{y}_{\mathrm{ij}}\right)=\prod_{\mathrm{j}-1}^{\mathrm{a}-1} \frac{1}{\sqrt{2 \pi \pi_{\mathrm{i}}^{2}}} \exp \left\{-\frac{1}{2 \sigma_{\mathrm{i}}^{2}}\left[\mathrm{y}_{\mathrm{ij}}-\left(\beta_{0 \mathrm{i}}+\beta_{\mathrm{ii}} \mathrm{I}_{\mathrm{j}}\right)^{2}\right]\right\}=\frac{1}{\left(\sqrt{2 \pi \sigma_{\mathrm{i}}^{2}}\right)^{\mathrm{a}}} \exp \left\{-\frac{1}{2 \sigma_{\mathrm{i}}^{2}} \sum_{\mathrm{j}=1}^{\mathrm{a}}\left[\mathrm{y}_{\mathrm{ij}}-\left(\beta_{0 \mathrm{i}}+\beta_{\mathrm{ii}} \mathrm{I}_{\mathrm{j}}\right)^{2}\right]\right\}, \forall_{\mathrm{i}} \quad \text { (Equation 5) }
$$

To estimate the adaptability and stability parameters, a priori distributions were assigned for the parameters. The following distributions were considered for $\beta_{0 \mathrm{i}}, \beta_{\mathrm{li}}$, and ${\sigma^{2}}_{\mathrm{di}}$ :

$$
\begin{gathered}
\beta_{0 \mathrm{i}} \sim \mathrm{N}\left(\mu_{0 \mathrm{i}}, \sigma_{0 \mathrm{i}}^{2}\right), \beta_{\mathrm{li}} \sim \mathrm{N}\left(\mu_{0 \mathrm{i}}, \sigma_{\mathrm{li}}^{2}\right) \\
\sigma_{\mathrm{di}}^{2} \sim \operatorname{GamaInv}\left(\alpha_{\mathrm{i}}: \beta_{\mathrm{i}}\right)
\end{gathered}
$$

The equal mean and variance for the reverse gamma values were calculated as follows, respectively:

$$
\begin{gathered}
\frac{\beta_{i}}{\alpha_{i}-1} \\
\frac{\beta_{i}^{2}}{\left(\alpha_{i}-1\right)^{2}\left(\alpha_{i}-2\right)}
\end{gathered}
$$

When we assumed independence between the parameters of these distributions, the joint a priori distributions for each genotype were given by:

$$
\begin{gathered}
\mathrm{P}_{\mathrm{i}}\left(\beta_{0 \mathrm{i}}, \beta_{\mathrm{li}}, \sigma_{1}^{2}, \mathrm{y}_{\mathrm{ij}}\right)=\frac{1}{\sqrt{2 \pi \sigma_{0 \mathrm{i}}^{2}}} \exp \left\{-\frac{1}{2 \sigma_{0 \mathrm{i}}^{2}}\left[\left(\beta_{0 \mathrm{i}}+\mu_{0 \mathrm{i}}\right)^{2}\right]\right\} \times \frac{1}{\sqrt{2 \pi \sigma_{\mathrm{li}}^{2}}} \exp \left\{-\frac{1}{2 \sigma_{\mathrm{li}}^{2}}\left[\left(\beta_{\mathrm{li}}+\mu_{\mathrm{li}}\right)^{2}\right]\right\} \times \sigma_{0 \mathrm{i}}^{2} \\
\frac{1}{\left[\beta_{1}^{\Delta i} \mathrm{G}\left(\alpha_{1}\right)\right]}\left(\frac{1}{\sigma_{1}^{2}}\right)^{\Delta i-1} \exp \left\{-\frac{1}{\beta_{1} \sigma_{1}^{2}}\right\} \infty \exp \left[-\frac{1}{2 \sigma_{1}^{2}}\left(\beta_{0 \mathrm{i}}+\mu_{0 \mathrm{i}}\right)^{2}\right] \times \frac{1}{\sqrt{2 \pi \sigma_{\mathrm{li}}^{2}}} \exp \left[-\frac{1}{2 \sigma_{\mathrm{li}}^{2}}\left(\beta_{\mathrm{li}}+\mu_{\mathrm{li}}\right)^{2}\right] \times\left(\frac{1}{\sigma_{1}^{2}}\right)^{\Delta-1-1} \exp \left\{-\frac{1}{\beta_{1} \sigma_{1}^{2}}\right\}
\end{gathered}
$$

To make inferences about the parameter of interest, the marginal a posteriori distributions must be obtained. When we denoted the parameter vectors for each genotype $\mathrm{i}$ using the following equation:

$$
\theta_{\mathrm{pi}}=\left(\beta_{1 \mathrm{i}}, \beta_{2 \mathrm{i}}, \sigma_{3 \mathrm{i}}^{2}\right)
$$

(where $\mathrm{P}=1,2,3$ ), the marginal a posteriori distribution for the parameter $\theta_{\mathrm{pi}}$ was obtained using the following integral: 


$$
\mathrm{P}\left(\theta_{\mathrm{pi}} \mid \mathrm{x}\right)=\int \mathrm{P}\left(\theta_{\mathrm{pi}} \mid \mathrm{x}\right) \mathrm{d} \theta_{\mathrm{pi}}
$$

(Equation 13)

(i.e., the integral in relation to all vector parameters with the exception of the p-th component).

In most cases, these integrals were complex and did not have exact solutions. To work around this problem, we used other methodologies. For example, we obtained a sample of the joint a posteriori distribution using the Markov chain and Monte Carlo (MCMC) method, which was used to determine the moments associated with the marginal distributions of interest (Cassela and George, 1992). In this study, the analyses were performed using R software ( $R$ Development Core Team, 2015) with codes developed by Nascimento et al. (2011), and the joint distribution sample was obtained using the MCMC regression function of the MCMC package.

To evaluate the influence of a priori information when estimating the adaptability and stability parameters, we utilized two different models: informative a priori distributions and minimally informative a priori distributions (Nascimento et al., 2011). In Model 1, the informative a priori information was derived from the application of meta-analysis techniques, which were characterized using information from the study by Corrêa et al. (2009).

The 13 genotypes evaluated in the trials were used as references for a priori specification. Therefore, all of the genotypes presented in Table 2 were considered for Bayesian analysis. Information was inserted into the analysis using the assumed values for $a$ priori distribution parameters (i.e., hyperparameters). These values were based on the mean and variance values of the samples that were composed using the parameter estimates obtained from the cited references (Table 2), which resulted in the following distributions:

$$
\begin{gathered}
\beta_{0 \mathrm{i}} \sim \mathrm{N}\left(\mu_{0 \mathrm{i}}=\bar{\beta}_{0 \mathrm{i}}, \sigma_{\mathrm{li}}^{2}=\operatorname{Var}\left(\bar{\beta}_{0 \mathrm{i}}\right)\right) \\
\beta_{\mathrm{li}} \sim \mathrm{N}\left(\mu_{\mathrm{li}}=\bar{\beta}_{\mathrm{li}}, \sigma_{\mathrm{li}}^{2}=\operatorname{Var}\left(\bar{\beta}_{0 \mathrm{i}}\right)\right) \\
\sigma_{\mathrm{di}}^{2} \sim \operatorname{GamaInv}\left(\alpha_{\mathrm{i}}, \beta_{\mathrm{i}}\right)
\end{gathered}
$$

where $\bar{\beta}_{0 \mathrm{i}}$ represents the means of the $\beta_{0 \mathrm{i}}$ estimates; $\bar{\beta}_{1 \mathrm{i}}$ represents the means of the $\beta_{\mathrm{li}}$ estimates; $\operatorname{Var}\left(\bar{\beta}_{0 \mathrm{i}}\right)$ is the variance of the mean $\bar{\beta}_{0 \mathrm{i}}$ values; $\operatorname{Var}\left(\bar{\beta}_{1 \mathrm{i}}\right)$ is the variance of the mean $\bar{\beta}_{1 \mathrm{i}}$ values; and $\alpha_{i}$ and $\beta_{i}$ represent values obtained using the following system resolution equations:

$$
\bar{\sigma}_{i}^{2}=\frac{\beta}{\alpha_{i}-1}
$$

(Equation 17)

$$
\operatorname{Var}\left(\bar{\sigma}_{i}^{2}\right)=\frac{\beta_{i}^{2}}{\left(\alpha_{i}-1\right)^{2}\left(\alpha_{i}-2\right)}
$$




$$
\alpha_{i}=\frac{\left(\sigma_{i}^{2}\right)^{3}}{\operatorname{Var}\left(\bar{\sigma}_{i}^{2}\right) \times \bar{\sigma}_{i}^{2}} \beta_{i}=\frac{\left(\sigma_{i}^{2}\right)^{3}}{\operatorname{Var}\left(\bar{\sigma}_{i}^{2}\right)+\bar{\sigma}_{i}^{2}}
$$

In Model 2, minimally informative a priori distributions were used, and these distributions represented probability distributions with large variance. The following distributions were adopted:

$$
\begin{gathered}
\beta_{0 \mathrm{i}} \sim \mathrm{N}\left(\mu_{0 \mathrm{i}}=\beta_{0 \mathrm{i} .} \sigma_{0 \mathrm{i}}^{2}=1,000,000\right) \\
\beta_{\mathrm{li}} \sim \mathrm{N}\left(\mu_{0 \mathrm{i}}=\beta_{0 \mathrm{i} .} \sigma_{\mathrm{li}}^{2}=100,000\right) \\
\left.\sigma_{\mathrm{i}}^{2} \sim \operatorname{GamaInv}\left(\alpha_{\mathrm{i}}=0.00001\right) ; \beta_{\mathrm{i}}=5,000\right)
\end{gathered}
$$

(Equation 22)

The comparisons between Models 1 and 2 (i.e., between informative and minimally informative a priori distributions) were performed using the Bayes factor calculation (Kass and Raftery, 1995), which was conducted using the Bayes Factor function of the MCMC package. According to Jeffreys (1961), Bayes factors can be interpreted as follows: FBij < 1 provides evidence in favor of model $\mathrm{j} ; 1 \leq \mathrm{FBij}<3$ provides moderate evidence in favor of model i; $3 \leq \mathrm{FBij}<10$ indicates substantial evidence in favor of model i; $10 \leq \mathrm{FBij}<$ 30 demonstrates strong evidence in favor of model i; $30 \leq \mathrm{FBij}<100$ provides very strong evidence in favor of model 1 ; and $\mathrm{FBij} \geq 100$ indicates decisive evidence in favor of model $\mathrm{i}$.

Regarding the stability parameter $\left(\sigma_{\mathrm{di}}^{2}\right)$, samples of its marginal distributions were obtained indirectly, because this parameter represents a function. When values for $\sigma_{i}^{2}$ were obtained indirectly in each iteration, we acquired values for $\sigma_{\mathrm{di}}^{2}$ using the following expression:

$$
\hat{\sigma}_{\mathrm{di}}^{2}=\hat{\sigma}_{\mathrm{i}}^{2}-(\mathrm{MSR} / \mathrm{r})
$$

(Equation 23)

where MSR is the mean square of the residue provided by ANOVA, and $r$ is the number of repetitions in the trial.

The hypotheses of interest were tested by constructing credibility ranges for the parameters, and the intervals were obtained directly from the marginal a posteriori distribution of the parameters. Thus, the credibility interval (CI) for $\theta_{\mathrm{i}}$, with a probability of covering $\delta$, is given by:

$$
\int_{-\infty}^{\theta^{*}} \mathrm{P}_{\mathrm{i}}\left(\theta_{\mathrm{i}}=\left(\beta_{0 \mathrm{i}}: \beta_{\mathrm{li}}: \sigma_{\mathrm{di}}^{2}\right) \mid \mathrm{y}_{\mathrm{ij}}\right) \mathrm{d} \theta_{\mathrm{i}}=\alpha / 2
$$

(Equation 24) 


$$
\int_{\theta^{*}}^{-\infty} \mathrm{P}_{\mathrm{i}}\left(\theta_{\mathrm{i}}=\left(\beta_{0 \mathrm{i}}: \beta_{\mathrm{li}}: \sigma_{\mathrm{di}}^{2}\right) \mid \mathrm{y}_{\mathrm{ij}}\right) \mathrm{d} \theta_{\mathrm{i}}=\alpha / 2
$$

(Equation 25)

where $\theta_{*}$ and $\theta^{*}$ represent the lower and upper limits of the CI, respectively. Since the Gibbs sampler is an iterative algorithm, it is necessary to check its convergence. In this study, the convergence was assessed by applying the Heidelberger and Welch (1983), Raftery and Lewis (1992), and Geweke (1992) criteria, which were implemented in the Bayesian Output Analysis package (BOA) of the R program (R Development Core Team, 2015).

Regarding Bayesian analyses of adaptability and stability for each parameter of the adopted regression model, 110,000 iterations in the Gibbs sampler algorithm with a warm period ("burn-in") of 10,000 iterations were considered. To obtain a non-correlated sample, we considered the spacing between the sampling points of two iterations ("thinning"), which resulted in a final sample size of 50,000. The samples represented samples of marginal $a$ posteriori distributions for each parameter under which the inference was conducted (Nascimento et al., 2011).

\section{RESULTS AND DISCUSSION}

In joint analyses, all of the effects were significant $(P \leq 0.01)$ (Table 3$)$, which indicated contrasts between the environments and the occurrence of genotypic differential responses to environmental effects. This could be confirmed by examining differences in the soil and climatic features of each environment, including altitude, latitude, longitude, climate type, soil type, rainfall, and temperature (Table 1). Similar results were obtained by Coimbra et al. (1999), Carbonell et al. (2004), Ribeiro et al. (2009), Pereira et al. (2009, 2011), and Torga et al. (2013) in previous studies, which found significant differences associated with the effects of genotypes, environments, and GE interactions when evaluating common genotypes in multi-environment trials in Brazil. The existence of significant GE interactions for grain yield indicated that the stability and adaptability analyses were suitable, and this result was further supported by the fact that edaphoclimatic factors had the greatest influence on the adaptability and stability of common bean genotypes.

Table 3. Summary of joint ANOVA for grain yield ( $\mathrm{Mg} / \mathrm{ha}$ ) of 13 common bean genotypes that were evaluated in six environments in the State of Mato Grosso do Sul.

\begin{tabular}{l|c|c}
\hline Sources of variation & d.f. & Mean square \\
\hline Blocks/Environment & 10 & $28,717.86$ \\
\hline Genotypes & 12 & $1,362,132.53^{*}$ \\
\hline Environment & 5 & $3,182,552.19^{*}$ \\
\hline Genotypes $\times$ Environment & 60 & $303,445.22^{*}$ \\
\hline Error & 146 & $22,387.42$ \\
\hline Mean (Mg/ha) & - & 1.89 \\
\hline Coefficient of variation (\%) & - & 10.96 \\
\hline
\end{tabular}

*Significant at a 0.01 probability level using the $\mathrm{F}$ test.

Regarding the convergence for all simulated chains, the dependency factor of Raftery and Lewis (1992) gave values lower than five, and p-values based on the criteria of Geweke (1992) were higher than the prefixed significance level $(\mathrm{P} \leq 0.05)$ (i.e., both criteria 
indicated convergence of the chains generated by the Gibbs sampler). In order to confirm this convergence, we also used the criteria of Heidelberger and Welch (1983), which determined whether the chain values were derived from a stationary distribution.

The adaptability and stability parameter estimated values were obtained by calculating the a posteriori means, which are presented together with their respective CIs in Table 4 . In Model 1 (informative a priori), of the 13 genotypes of common bean evaluated by the Bayesian approach, the EMGOPA-201, BAMBUÍ, CNF 4999, CNF 4129 A 54, and CNFv 8025 genotypes were classified as having specific adaptability to favorable environments (LI $\beta_{1 \mathrm{i}}>1$ ). The IAPAR 14 and IAC CARIOCA ETE genotypes presented specific adaptability to unfavorable environments (LS $\beta_{1 \mathrm{i}}<1$ ). The other genotypes were classified as having general adaptability and stability, since the value of 1 fell within a CI of $95 \%$. However, when considering the analysis of genotypes under Model 2 conditions (minimally informative a priori), all genotypes of common bean showed specific adaptability to unfavorable environments ( $\left.\mathrm{LI} \beta_{1 \mathrm{i}}<1\right)$. Therefore, it is possible to infer that the use of the frequentist model, in which a priori information is not taken into account, tends to conclude that the genotypes of common bean exhibit stability and adaptability to different environments, but this does not favor reliable genotype recommendations. Nascimento et al. (2011), Couto et al. (2015), and Teodoro et al. (2015) obtained similar results after evaluating the adaptability and phenotypic stability of alfalfa, popcorn, and cowpea genotypes, respectively.

Table 4. Estimates of a posteriori mean $\left(\bar{\beta}_{0 i}\right.$, in $\left.\mathrm{Mg} / \mathrm{ha}\right)$ and credibility intervals (95\%) of the adaptability $\left(\bar{\beta}_{1 i}\right)$ and stability $\left(\bar{\sigma}_{i}^{2}\right)$ parameters for common bean genotypes when considering informative and minimally informative a priori distributions.

\begin{tabular}{|c|c|c|c|c|c|c|c|c|c|c|}
\hline Genotype & $\mathrm{LI} \bar{\beta}_{0 i}$ & $\bar{\beta}_{0 i}$ & $\operatorname{LS} \bar{\beta}_{0 i}$ & $\mathrm{LI} \bar{\beta}_{1 i}$ & $\bar{\beta}_{1 i}$ & $\operatorname{LS} \bar{\beta}_{1 i}$ & $\bar{\sigma}_{i}^{2} \times 1000$ & $\mathrm{LI} \bar{\sigma}_{d i}^{2} \times 1000$ & $\bar{\sigma}_{d i}^{2} \times 1000$ & LS $\bar{\sigma}_{d i}^{2} \times 1000$ \\
\hline \multicolumn{11}{|l|}{ Informative a priori } \\
\hline RUDÁ & 2.03 & 2.18 & 2.33 & 0.68 & 0.94 & 1.20 & 35.94 & 12.05 & 29.01 & 60.09 \\
\hline APORE & 2.08 & 2.21 & 2.34 & 0.34 & 0.57 & 0.82 & 27.12 & 7.31 & 20.21 & 44.04 \\
\hline XAMEGO & 1.74 & 1.86 & 1.99 & 0.65 & 0.88 & 1.11 & 23.97 & 5.69 & 17.06 & 37.92 \\
\hline PÉROLA & 1.56 & 1.69 & 1.82 & 0.58 & 0.82 & 1.06 & 28.02 & 7.84 & 21.11 & 45.38 \\
\hline OURO NEGRO & 1.62 & 1.75 & 1.88 & 0.89 & 1.13 & 1.38 & 27.69 & 7.59 & 20.78 & 45.23 \\
\hline DIAMANTE NEGRO & 1.60 & 1.68 & 1.77 & 0.83 & 0.99 & 1.16 & 10.81 & -1.24 & 3.90 & 13.36 \\
\hline IAPAR 14 & 1.81 & 2.03 & 2.24 & 0.20 & 0.53 & 0.87 & 80.97 & 35.69 & 74.06 & 144.29 \\
\hline EMGOPA -201 & 1.85 & 1.97 & 2.10 & 1.05 & 1.29 & 1.51 & 23.96 & 5.63 & 17.05 & 37.93 \\
\hline IAC CARIOCA ETE & 1.64 & 1.70 & 1.76 & 0.22 & 0.34 & 0.47 & 5.29 & -4.15 & -1.62 & 3.04 \\
\hline BAMBUÍ & 1.91 & 2.07 & 2.22 & 1.19 & 1.47 & 1.73 & 39.55 & 13.74 & 32.64 & 67.34 \\
\hline CNF 4999 & 1.64 & 1.75 & 1.87 & 1.21 & 1.44 & 1.65 & 20.59 & 3.81 & 13.68 & 31.81 \\
\hline CNF 4129 A 54 & 1.29 & 1.47 & 1.64 & 1.04 & 1.35 & 1.64 & 51.11 & 19.54 & 44.19 & 89.61 \\
\hline CNFv 8025 & 2.03 & 2.14 & 2.25 & 1.01 & 1.22 & 1.43 & 19.60 & 3.39 & 12.69 & 29.75 \\
\hline \multicolumn{11}{|c|}{ Minimally informative $a$ priori } \\
\hline RUDÁ & 1.70 & 2.17 & 2.62 & -0.05 & 0.93 & 1.91 & 32.84 & 52.32 & 32.15 & 134.41 \\
\hline APORÉ & 1.79 & 2.19 & 2.58 & -0.34 & 0.51 & 1.35 & 24.47 & 37.17 & 23.78 & 99.81 \\
\hline XAMEGO & 1.47 & 1.85 & 2.22 & 0.06 & 0.86 & 165 & 21.85 & 32.46 & 21.16 & 88.94 \\
\hline PÉROLA & 1.27 & 1.68 & 2.08 & -0.04 & 0.82 & 1.68 & 25.59 & 39.25 & 24.89 & 104.21 \\
\hline OURO NEGRO & 1.32 & 1.73 & 2.12 & 0.21 & 1.06 & 1.91 & 24.89 & 37.99 & 24.19 & 101.41 \\
\hline DIAMANTE NEGRO & 1.42 & 1.68 & 1.93 & 0.46 & 0.99 & 1.53 & 9.97 & 10.99 & 9.28 & 40.08 \\
\hline IAPAR 14 & 1.34 & 2.03 & 2.69 & -1.10 & 0.35 & 1.79 & 71.93 & 12.39 & 71.24 & 296.01 \\
\hline EMGOPA -201 & 1.57 & 1.95 & 2.31 & 0.55 & 1.34 & 2.13 & 21.61 & 32.03 & 20.92 & 87.97 \\
\hline IAC CARIOCA ETE & 1.52 & 1.69 & 1.87 & -0.05 & 0.32 & 0.70 & 49.73 & 20.00 & 42.81 & 195.89 \\
\hline BAMBUÍ & 1.62 & 2.10 & 2.56 & 0.54 & 1.55 & 2.56 & 35.20 & 56.62 & 34.51 & 144.21 \\
\hline CNF 4999 & 1.40 & 1.75 & 2.09 & 0.78 & 1.51 & 2.24 & 18.44 & 26.31 & 17.75 & 74.85 \\
\hline CNF 4129 A 54 & 9.30 & 1.47 & 1.99 & 0.42 & 1.55 & 2.67 & 43.94 & 72.75 & 43.24 & 179.61 \\
\hline CNFv 8025 & 1.80 & 2.15 & 2.48 & 0.50 & 1.22 & 1.94 & 17.92 & 25.33 & 17.23 & 72.78 \\
\hline
\end{tabular}


By comparing the estimates of the parameters obtained using the two models, similar differences in magnitude between the parameters were observed. Thus, it is necessary to determine which of the two models exhibited a higher quality setting, and this answer was provided using Bayes factor calculations (Nascimento et al., 2011). All of the genotypes evaluated exhibited Bayes factors that were greater than 41 (Table 5), resembling the results obtained by Nascimento et al. (2011), Couto et al. (2015), and Teodoro et al. (2015).

Table 5. Values obtained for Bayes factors (BF) of models compared using informative a priori (i) and minimally informative a priori (j) distributions for the common bean genotypes evaluated.

\begin{tabular}{l|l}
\hline Genotype & $\mathrm{BF}_{\mathrm{ij}}$ \\
\hline RUDÁ & 55.80 \\
\hline APORÉ & 53.90 \\
\hline XAMEGO & 52.80 \\
\hline PÉROLA & 53.90 \\
\hline OURO NEGRO & 54.40 \\
\hline DIAMANTE NEGRO & 46.20 \\
\hline IAPAR 14 & 63.10 \\
\hline EMGOPA -201 & 53.60 \\
\hline IAC CARIOCA ETE & 41.10 \\
\hline BAMBUÍ & 58.30 \\
\hline CNF 4999 & 52.00 \\
\hline CNF 4129 A 54 & 59.80 \\
\hline CNFv 8025 & 51.10 \\
\hline RUDÁ & 55.80 \\
\hline APORÉ & 53.90 \\
\hline XAMEGO & 52.80 \\
\hline
\end{tabular}

These results indicated that the use of informative a priori distributions provided more accurate results. Even though the a priori information for each genotype was based on a single study, similar results were found in studies that evaluated the adaptability and phenotypic stability of the dry matter yield of alfalfa genotypes (Nascimento et al., 2011), popcorn grain yield (Couto et al., 2015), and cowpea grain yield (Teodoro et al., 2015; Barroso et al., 2016). Therefore, it is expected that the results will be more precise in studies examining the stability and adaptability of other crops with more available information for meta-analysis.

The Bayesian inference, in conjunction with the Eberhart and Russell method (1966), was an effective method for the selection of common bean genotypes with high adaptability and phenotypic stability. Moreover, Bayes factors indicated that the use of informative a priori distributions provided more accurate results than the use of minimally a priori distributions. According to Bayesian inference, the EMGOPA-201, BAMBUÍ, CNF 4999, CNF 4129 A 54, and CNFv 8025 genotypes had specific adaptability to favorable environments, while the IAPAR 14 and IAC CARIOCA ETE genotypes presented specific adaptability to unfavorable environments.

\section{Conflicts of interest}

The authors declare no conflict of interest.

\section{ACKNOWLEDGMENTS}

We thank the Brazilian Federal Agency for Support and Evaluation of Graduate Education (CAPES) and the National Council for Scientific and Technological Development (CNPq) for financial support. 


\section{REFERENCES}

Banzatto DA and Kronka SN (2006). Experimentação agrícola. FUNEP, Jaboticabal.

Barroso LMA, Teodoro PE, Nascimento M, Torres FE, et al. (2016). Bayesian approach increases accuracy when selecting cowpea genotypes with high adaptability and phenotypic stability. Genet. Mol. Res. 15: gmr.15017625.

Carbonell SAM, Azevedo Filho JA, Dias LAS, Garcia AAF, et al. (2004). Common bean cultivars and lines interactions with environments. Sci. Agric. 61: 169-177. http://dx.doi.org/10.1590/S0103-90162004000200008

Cassela G and George EI (1992). Explaining the Gibbs sampler. Am. Stat. 46: 167-174.

CONAB (Companhia Nacional de Abastecimento) (2015). Acompanhamento da safra brasileira: Grãos 2014/2014 Décimo segundo levantamento. Available at [http://www.conab.gov.br]. Accessed December 19, 2015.

Corrêa AM, Gonçalves M, Souza LCF, Rodrigues ET, et al. (2009). Adaptabilidade e estabilidade de genótipos de feijão cultivados em duas localidades de Mato Grosso do Sul. Pesq. Agropec. Gau. 15: 135-144.

Coimbra JLM, Carvalho FIF, Hemp S and Silva SA (1999). Adaptability and phenotypic stability of collor bean genotypes (Phaseolus vulgaris L.) in three different environments. Cienc. Rural 29: 441-448. http://dx.doi.org/10.1590/S0103$\underline{84781999000300010}$

Cotes JM, Crossa J, Sanches J and Cornelius PL (2006). A Bayesian approach for assessing the stability of genotypes. Crop Sci. 46: 2654-2665. http://dx.doi.org/10.2135/cropsci2006.04.0227

Couto MF, Nascimento M, Amaral AT, Silva FF, et al. (2015). Eberhart and Russel's bayesian method in the selection of popcorn cultivars. Crop Sci. 55: 571-577. http://dx.doi.org/10.2135/cropsci2014.07.0498

Cruz CD and Regazzi AJ (2007). Modelos biométricos aplicados ao melhoramento genético. Imprensa Universitária, Viçosa.

Eberhart SA and Russell WA (1966). Stability parameters for comparing varieties. Crop Sci. 6: 36-40. http://dx.doi. org/10.2135/cropsci1966.0011183X000600010011x

FAO (Food and Agriculture Organization of the United Nations) (2013). Production: Crops. Available at [http://faostat. fao.org]. Accessed December 19, 2015.

Gauch HG (2006). Statistical analysis of yield trials by AMMI and GGE. Crop Sci. 46: 1488-1500. http://dx.doi. org/10.2135/cropsci2005.07-0193

Geweke J (1992). Evaluating the accuracy of sampling-based approaches to the calculation of posterior moments. In: Bayesian statistics (Bernardo JM, Berger JO, David AP and Smith AFM, eds.). Oxford University, New York, 625-631.

Heidelberger P and Welch PD (1983). Simulation run length control in the presence of an initial transient. Oper. Res. 31: 1109-1144. http://dx.doi.org/10.1287/opre.31.6.1109

Jeffreys H (1961). Theory of probability. Claredon, Oxford.

Kass RE and Raftery AE (1995). Bayes factors. J. Am. Stat. Assoc. 90: 773-795. http://dx.doi.org/10.1080/01621459.19 $\underline{95.10476572}$

Nascimento M, Silva FF, Sáfadi T, Nascimento ACC, et al. (2011). Abordagem bayesiana para avaliação da adaptabilidade e estabilidade de genotipos de alfafa. Pesquisa Agropecu. Bras. 46: 26-32. http://dx.doi.org/10.1590/S0100$\underline{204 X 2011000100004}$

Pereira HS, Melo LC, Faria LC, Peloso MJD, et al. (2009). Adaptability and stability of common bean genotypes with carioca grain type for central Brazil. Pesquisa Agropecu. Bras. 44: 29-37. http://dx.doi.org/10.1590/S0100$\underline{204 X 2009000100005}$

Pereira HS, Melo LC, Peloso MJD, Faria LC, et al. (2011). Complex interaction between genotypes and sowing seasons of carioca common bean in Goiás/Distrito Federal. Crop Breed. Appl. Biotechnol. 11: 207-215.

R Development Core Team (2015). R: a language and environment for statistical computing. Vienna: R Foundation for Statistical Computing. http://www.R- project.org. Accessed April 15, 2015.

Raftery AE and Lewis SM (1992). [practical markov chain monte carlo]: comment: one long run with diagnostics: implementation strategies for Markov chain Monte Carlo. Stat. Sci. 7: 493-497. http://dx.doi.org/10.1214/ $\underline{\text { ss/1177011143 }}$

Ribeiro NF, Souza JF, Antunes IF and Poersch NL (2009). Yield stability of common bean cultivars of different commercial groups in Rio Grande do Sul State. Bragantia 68: 339-346. http://dx.doi.org/10.1590/S0006-87052009000200007

Silva MAG, Peternelli LA, Nascimento M and Silva FL (2013). Modelos mistos na seleção de famílias de cana de açúcar aparentados sob o enfoque clássico e bayesiano. Rev. Bras. Biol. 31: 1-12.

Teodoro PE, Nascimento M, Torres FE, Barroso LMA, et al. (2015). Perspectiva baysiana na seleção de genótipos de feijão-caupi em ensaios de valor de cultivo e uso. Pesquisa Agropecu. Bras. 50: 878-885. http://dx.doi.org/10.1590/ $\underline{\text { S0100-204X2015001000003 }}$

Torga PP, Melo PGS, Pereira HS, Faria LC, et al. (2013). Interaction of common beans cultivars of the black group with years, locations and sowing seasons. Euphytica 189: 239-248. http://dx.doi.org/10.1007/s10681-012-0793-y 